\title{
Frederica effects database update within the EMRAS-II programme: Contributing to evaluate the environmental impact of ionizing radiation
}

\author{
A. Real ${ }^{1}$, N. Horemans ${ }^{2}$, L. Newsome ${ }^{3}$, A. Oudalova ${ }^{4}$, K. Stark ${ }^{5}$, C. Willrodt ${ }^{6}$, \\ S. Yoshida ${ }^{7}$ and T. Hinton ${ }^{8}$ \\ ${ }^{1}$ Radiation Protection of Public and Environment, CIEMAT, Madrid, Spain \\ e-mail: almudena.real@ciemat.es \\ ${ }^{2}$ Biosphere Impact Studies, SCK-CEN, Mol, Belgium \\ ${ }^{3}$ Chemicals and Radioactive Substances, Environment Agency, UK \\ ${ }^{4}$ Russian Institute of Agricultural Radiology \& Agroecology, Obninsk, Russia \\ ${ }^{5}$ Department of Systems Ecology, Stockholm University, Sweden \\ ${ }^{6}$ Federal Office for Radiation Protection (BfS), Salzgitter, Germany \\ ${ }^{7}$ Research Center for Radiation Protection, National Institute of Radiological Sciences, \\ Chiba-shi, Japan \\ ${ }^{8}$ Institut de Radioprotection et de Sûreté Nucléaire (IRSN), Cadarache, France
}

The present work has been done within the IAEA Environmental Modelling for Radiation Safety Programme. EMRAS-II aims to improve the capabilities in the field of environmental radiation dose assessment by means of acquisition of improved data for model testing, comparison, reaching consensus on modelling philosophies, approaches and parameter values, development of improved methods and exchange of information.

The Programme is focused on areas where uncertainties remain in the predictive capability of environmental models, thus allowing the improvement of existing methods and the development of new approaches to strengthen the evaluation of the radiological impact to man, as well as to flora and fauna, arising from radionuclides released or present in the environment.

Within EMRAS-II three Working Groups (WG4-6) are devoted to Reference Approaches for Biota Dose Assessment. The WP-6, Biota Dose Effects Modelling, is interested in understanding the impacts on flora and fauna arising from radioactive compounds released or present in the environment. To do so it requires knowledge of exposure conditions, life history characteristics of the organisms exposed, estimation of absorbed dose, derivation of dose-effects relationships, and the scientific establishment of dose (dose rate) screening levels that are believed to adequately protect the environment.

One task within WP-6 has been to update the FREDERICA Dose-Effect database, since the knowledge of the biological effects produced in wildlife by different types of radiation, under different exposure situations, is a key issue in radiological risk assessment. Besides, the information included in the database is the foundation upon which new dose-response relationships and taxonomically-expanded screening level values are being developed [1].

FREDERICA was originally developed during the European Project ERICA [2], and was mainly the result of merging two existing effects databases: FRED and EPIC [3, 4]. Details of the FREDERICA database have been described elsewhere [5]. Briefly, the data on radiation-induced effects are organised into 16 different wildlife groups (amphibians, aquatic invertebrates, aquatic plants, bacteria, birds, crustaceans, fish, fungi, insects, mammals, molluscs, mosses/lichens, reptiles, soil fauna, terrestrial 
plants and zooplankton). The biological effects studied have been classified in four main umbrella endpoints: reproductive capacity, mortality, morbidity and mutation. Information on the exposure regime, radiation type and source, life stage at irradiation has also been recorded for each study performed in the reference.

FREDERICA database is freely available online at http://87.84.223.229/fred/mainpage.asp, with the only requirement for the users to register before accessing the database. Thus, anyone can both search the data compiled and submit their effects data to be included in the database. FREDERICA has several search options including searches by author, keywords, source of radiation (internal, external etc); radiation type or radionuclide, endpoint, species (or a group of them) within a wildlife group. There is also the possibility of doing a sequential search of wildlife group, umbrella endpoint for a specific dose or dose rate range. The outputs from each search can be exported to an Excellßspreadsheet.

At the end of the ERICA Project, the database contained over 1,500 references (over 29,400 data entries) published between 1945 and 2006. Within the information compiled, 64\% of the data sets were obtained after acute or transitory irradiation, whereas $36 \%$ of the data sets were obtained after chronic irradiation. Fish, mammals and terrestrial plants were the wildlife groups most widely reported in chronic irradiation studies, representing all together $70.5 \%$ of the chronic data. The information was scarce or non-existing for amphibians, aquatic plants, bacteria, crustacean, fungi, moss and lichen, reptiles and zooplankton [5].

Since FREDERICA was last updated in 2006, within the WP-6 of the EMRAS-II Programme a Task was planned to include in the database the information published since 2006, as well as data from Japanese, Russian and Ukrainian literature. Thus, a literature survey was done rendering over 600 papers. However not all of them were suitable for inclusion in the database (e.g. review articles without detailed experimental description). Around 250 references out of 600 were published in Russian. Thanks to the effort made by IAEA, the translation of these papers could be initiated, and a number of them were included in the database.

References newly included in FREDERICA went through a Quality Control analysis (QC), using the same criteria established in the ERICA project (dosimetry, experimental design and statistics). The objective of this analysis was to determine whether or not the reference gives suitable and sufficient information to be used in the process of defining biological effect levels. Each paper had a score between 0 and 80 points.

In total 186 new references were added to FREDERICA, 33 of which were translations of Russian papers. Studies performed under acute radiation exposures were more common than those undertaken after chronic irradiations (60\% and $40 \%$, respectively). The most commonly studied wildlife groups were mammals (33\%), plants (12\%), amphibians (10\%), insects (7\%) and protozoa (7\%). Regarding the biological endpoint, reproductive capacity, mortality and morbidity were most frequently analysed, followed by DNA damage. Regarding the QC analysis results, more than $65 \%$ of the papers analysed had a score higher than 35 points.

The new data included in FREDERICA during the EMRAS-II Programme is being used within WP-6 to develop dose-response relationships in order to derive homogeneous toxicity endpoints (i.e. ED50, EDR10) for the implementation of species sensitivity distributions (SSDs) and the corresponding derivation of threshold protection values.

It has to be highlighted that FREDERICA database is the most complete source of information on the biological effects of ionising radiation on flora and fauna, available nowadays. Thus, different national and international organizations have used the database to review the information available on effects, for environmental risk assessment purposes.

\section{References}

[1] Garnier-Laplace, J., Della-Vedova, C., Gilbin, R., Copplestone, D., Hingston, J.L., Ciffroy, P., 2006. First derivation of predicted-no-effect values for freshwater and terrestrial ecosystems exposed to radioactive substances. Environmental Science and Technology 40 (20), 6498-6505. 
[2] Beresford, N.A., Brown, J., Copplestone, D., Garnier-Laplace, J., Howard, B.J., Larsson, C.-M., Oughton, D., Prohl, G., Zinger, I., 2007. An integrated approach to the assessment and management of environmental risk from ionising radiation: description of purpose, methodology and application. ERICA Deliverable: D-ERICA. EC Contract No FI6R-CT-2004-508847.

[3] Larsson, C.-M., Jones, C., Gomez-Ros, J.M., Zinger, I., 2004. Framework for assessment of environmental impact of ionising radiation in major European ecosystems. FASSET Deliverable D6, FASSET Contract No FIGECT-2000-00102.

[4] Sazykina, T., Jaworska, A., Brown, J., 2002. Report on dose effects relationships for reference (or related) Arctic biota. EPIC database 'Radiation effects on biota'. EPIC Project Deliverable 5. EPIC Inco-Copernicus Project Contract ICA2-CT-2000-10032.

[5] Copplestone D., Hingston J., Real A. 2008. The development and purpose of the FREDERICA radiation effects database. Journal of Environmental Radioactivity 99: 1456-1463. 